\title{
Genetic variation and differentiation in populations of a threatened tree, Magnolia stellata: factors influencing the level of within-population genetic variation
}

\author{
I Tamaki, S Setsuko and N Tomaru \\ Laboratory of Forest Ecology and Physiology, Graduate School of Bioagricultural Sciences, Nagoya University, Nagoya, Japan
}

\begin{abstract}
Genetic variation and differentiation in Magnolia stellata were studied in 20 populations distributed across most of the species' range using 10 microsatellite markers, and the factors influencing their levels of within-population genetic variation were examined. Generally, populations distributed intermittently from southern Gifu to central Aichi Prefectures showed substantially higher levels of genetic variation (exceptions included populations located at unusually high altitude sites or western and southern edges of the range) than more isolated populations on the Atsumi Peninsula of southern Aichi Prefecture and in northern Mie Prefecture. Significant isolation-by-distance patterns were detected in genetic differentiation among the studied populations, and a
\end{abstract}

neighbor-joining tree based on $D_{\mathrm{A}}$ distances among the populations reflected well the geographical positions of the populations. The level of within-population genetic variation was significantly influenced not only by the size of the populations (represented by the number of reproductive individuals) but also by their degree of isolation (represented by the number of populations within a radius of $0.5 \mathrm{~km}$ around them). Therefore, areas within radii of $0.5 \mathrm{~km}$ may encompass M. stellata metapopulations, in which gene flow may usually occur. We suggest that this area may be a suitable standard for constructing conservation units for the species.

Heredity (2008) 100, 415-423; doi:10.1038/sj.hdy.6801097; published online 23 January 2008

Keywords: conservation; genetic diversity; isolation; Magnoliaceae; metapopulation; population size

\section{Introduction}

Endangered species, whose populations are in many cases small and isolated, are susceptible to loss of withinpopulation genetic variation by genetic drift, which results in random fluctuations of allele frequencies. Loss of genetic variation reduces the evolutionary potential of populations to adapt to changing environments and increases the likelihood of biparental inbreeding, which decreases the fitness of progenies (Ellstrand and Elam, 1993; Frankham, 2005; Leim et al., 2006; Ouborg et al., 2006). Consequently, affected populations tend to decline and can fall into an 'extinction vortex' (Gilpine and Soule, 1986). Thus, detailed information on withinand among-population genetic variation over species' ranges and the factors influencing their levels of within-population genetic variation are needed to conserve such populations of endangered species.

Two factors that are believed to strongly influence the level of genetic variation within populations are the effective population size and degree of population isolation (Cruzan, 2001; Silvertown and Charlesworth,

Correspondence: I Tamaki, c/o Professor N Tomaru, Laboratory of Forest Ecology and Physiology, Graduate School of Bioagricultural Sciences, Nagoya University, Furo-Cho Chikusa-Ku, Nagoya 464-8601, Japan.

E-mail: garageit@gmail.com

Received 18 June 2007; revised 4 December 2007; accepted 14 December 2007; published online 23 January 2008
2001; Ouborg et al., 2006). Thus, it is important to consider the effects of these variables in analyses of genetic variation, but choosing the best measures for them is not straightforward. Many authors have used the actual number of individuals within investigated populations as a measure of population size, assuming that it is correlated with their effective population size, and found stronger relationships between this variable and genetic variation (for example, Young et al., 1999; Galeuchet et al., 2005; Gao, 2005; Leim et al., 2006). The degree of population isolation can be quantified by measuring positional relationships between a focal population and its surrounding populations. The simplest way of doing this is to measure the distance to the nearest population. This approach has been used by various authors (for example, Llorens et al., 2004; Galeuchet et al., 2005; Lu et al., 2005), but few have found significant relationships between this parameter and genetic variation ( $\mathrm{Lu}$ et al., 2005), probably because it provides a too simplistic indication of isolation (Moilanen and Nieminen, 2002). The cited authors studied possible connectivity measures in spatial ecology and recommended use of a 'buffer measure' based on the number of populations within a given radius around the focal population rather than simply the distance to the nearest population.

The species studied here, Magnolia stellata (Sieb. et Zucc.) Maxim., is a threatened tree species endemic to the Tokai region of central Japan (Environment 
Agency of Japan, 2000). It occurs in swampy places such as small rivers and marshes (Ueda, 1988) and at 40-700 m (mainly 200-500 m) elevations (Japan Association for Shidekobushi Conservation, 1996), and forms hierarchical metapopulation structures with sets of adjacent local populations (Setsuko et al., 2007). About $75 \%$ of these local populations are comprised of less than 100 individuals (Japan Association for Shidekobushi Conservation, 1996). Most populations are intermittently distributed from southern Gifu to central Aichi Prefectures, but a small number of populations are isolated on the Atsumi Peninsula of southern Aichi Prefecture and in northern Mie Prefecture (Figure 1; Japan Association for Shidekobushi Conservation 1996). Since habitat destruction and vegetation succession have decreased both the numbers of populations and numbers of individuals within each population, the species is now listed as 'vulnerable' in the Japanese Red Data Book (Environment Agency of Japan, 2000). However, only a few populations are currently protected, including several designated as natural monuments by the national government, or authorities in Prefectures or cities.

The genetic variation and differentiation in $M$. stellata populations have been investigated in three previous studies. First, Kawahara and Yoshimaru (1995) investigated nine populations using 15 allozyme markers, and found that the level of within-population genetic variation was lower in the isolated populations, while there was a high level of genetic differentiation among all populations $\left(G_{\mathrm{ST}}=0.254\right)$. In the cited study, however, few populations were sampled from the central part of the species' range. Second, Nakashima and Sakai (2003) investigated 14 populations sampled solely from the Tono region (southeastern Gifu Prefecture) using 10 allozyme markers, but did not identify the factors influencing the level of within-population genetic variation. Third, Ueno et al. (2005) investigated 11 populations, including the nine examined by Kawahara and Yoshimaru (1995), using four microsatellite markers developed in M. obovata, and also failed to identify

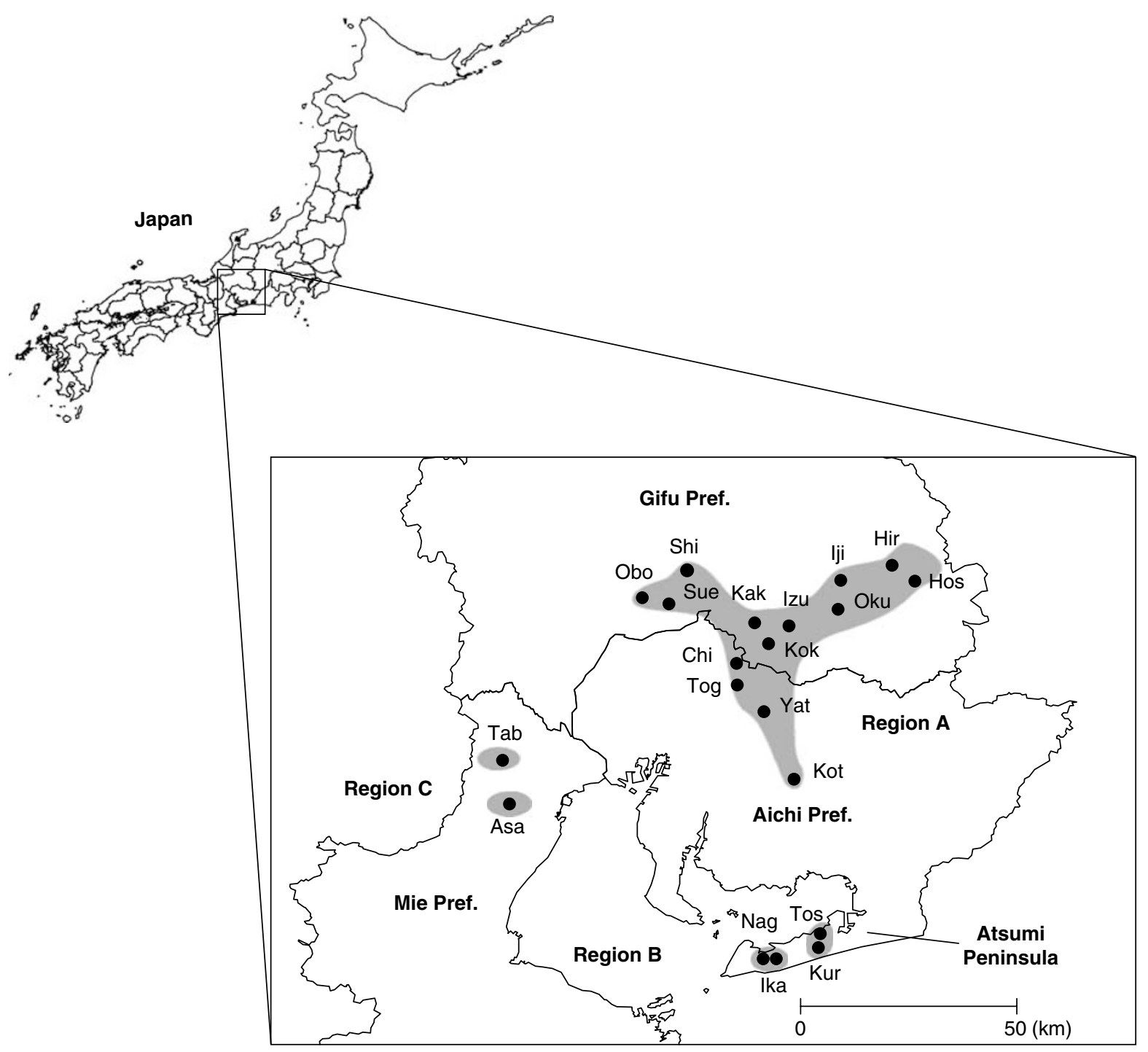

Figure 1 Locations of the 20 sampled Magnolia stellata populations (black dots) and the species' range (grey areas). Populations are represented by the codes listed in Table 1. 
factors influencing the level of within-population genetic variation, although they did detect some regional genetic structure. Contributory reasons for the failure of these three studies, and various studies of other species, to detect the factors influencing the level of within-population genetic variation were probably the regionally biased sampling of small numbers of populations and low resolution of the genetic markers used (allozymes and small numbers of microsatellites). Microsatellite makers, especially those developed in target species, generally have far larger numbers of alleles, including many rare alleles, than allozyme markers. Since the number of alleles is susceptible to random genetic drift, microsatellite markers are also suitable for detecting reductions in within-population genetic variation associated with random genetic drift. Thirty microsatellite markers were recently developed in M. stellata (Setsuko et al., 2005). We hypothesized that use of these markers to investigate a large number of populations extensively sampled from the species' range would allow us to identify factors influencing their levels of within-population genetic variation, which could not be detected in the previous studies.

The objectives of this study were (i) to estimate withinand among-population genetic variation in $20 \mathrm{M}$. stellata populations distributed across most of the species' range using 10 microsatellite markers, nine of which were developed in M. stellata (Setsuko et al., 2005) and one developed in the related species M. obovata (Isagi et al., 1999); (ii) to identify the factors influencing the level of within-population genetic variation, focusing on the effects of variations in the number of reproductive individuals within each population and the degree of population isolation represented by the number of surrounding populations and (iii) to consider possible conservation strategies for this species based on the findings.

\section{Materials and methods}

\section{Study species and population sampling}

M. stellata is a deciduous broad-leaved tree that grows up to $10 \mathrm{~m}$ in height and $20 \mathrm{~cm}$ in diameter at breast height. It reproduces both by seeds and by clonal growth (sprouts and layering) (Gotoh et al., 1998; Setsuko et al., 2004). Flowers are bisexual, protogynous and pollinated by insects, and mixed mating occurs (Hirayama et al., 2005). Fruits are aggregated, with at most two red seeds per follicle that may be dispersed by birds (Callaway, 1994).

The natural range of $M$. stellata was roughly divided into three regions: southern Gifu to central Aichi Prefectures (region A); the Atsumi Peninsula in southern Aichi Prefecture (region B) and northern Mie Prefecture (region C) (Figure 1). Twenty populations were randomly selected across its natural range as study populations (Figure1 and Table 1). A population was defined as an aggregation of individuals along streams or in marshes. We counted the number of reproductive individuals in flowering seasons in each population and defined this parameter as the population size. For DNA analysis, leaf samples were collected from 27 to 77 reproductive individuals in each population during 2004-2006 and stored at $-30{ }^{\circ} \mathrm{C}$ until DNA extraction.

\section{DNA extraction, PCR amplification and microsatellite analysis}

Genomic DNA was extracted from the sampled leaves using the hexadecyltrimethylammonium bromide method (Murray and Thompson, 1980) with minor modifications. Genotypes were determined using 10 microsatellite markers: nine (stm0148, stm0184, stm0191, stm0222, stm0223, stm0251, stm0334, stm0353 and stm0423) developed for M. stellata (Setsuko et al., 2005),

Table 1 Location, sample size and population size of the 20 investigated Magnolia stellata populations

\begin{tabular}{|c|c|c|c|c|c|}
\hline Population name & Population code & Latitude (N) & Longitude $(E)$ & Sample size & Population size \\
\hline \multicolumn{6}{|l|}{ Region A } \\
\hline Hirukawa & Hir & $35^{\circ} 31^{\prime} 43^{\prime \prime}$ & $137^{\circ} 24^{\prime} 41^{\prime \prime}$ & 29 & 101 \\
\hline Hoshigami & Hos & $35^{\circ} 29^{\prime} 30^{\prime \prime}$ & $137^{\circ} 27^{\prime} 52^{\prime \prime}$ & 30 & 257 \\
\hline $\mathrm{Iji}$ & Iji & $35^{\circ} 29^{\prime} 39^{\prime \prime}$ & $137^{\circ} 17^{\prime} 35^{\prime \prime}$ & 30 & 56 \\
\hline Izumi & Izu & $35^{\circ} 23^{\prime} 20^{\prime \prime}$ & $137^{\circ} 10^{\prime} 23^{\prime \prime}$ & 29 & 70 \\
\hline Kakishita & Kak & $35^{\circ} 23^{\prime} 44^{\prime \prime}$ & $137^{\circ} 05^{\prime} 39^{\prime \prime}$ & 31 & 54 \\
\hline Kokeizan & Kok & $35^{\circ} 20^{\prime} 50^{\prime \prime}$ & $137^{\circ} 07^{\prime} 35^{\prime \prime}$ & 30 & 339 \\
\hline Obora & Obo & $35^{\circ} 27^{\prime} 13^{\prime \prime}$ & $136^{\circ} 51^{\prime} 53^{\prime \prime}$ & 27 & 42 \\
\hline Okute & $\mathrm{Oku}$ & $35^{\circ} 25^{\prime} 37^{\prime \prime}$ & $137^{\circ} 17^{\prime} 13^{\prime \prime}$ & 67 & 69 \\
\hline Shizuno & Shi & $35^{\circ} 31^{\prime} 00^{\prime \prime}$ & $136^{\circ} 56^{\prime} 17^{\prime \prime}$ & 32 & 61 \\
\hline Sue & Sue & $35^{\circ} 26^{\prime} 23^{\prime \prime}$ & $136^{\circ} 53^{\prime} 46^{\prime \prime}$ & 30 & 156 \\
\hline Chikusui-ike & Chi & $35^{\circ} 18^{\prime} 07^{\prime \prime}$ & $137^{\circ} 03^{\prime} 09^{\prime \prime}$ & 34 & 108 \\
\hline Kotohira & Kot & $35^{\circ} 02^{\prime} 05^{\prime \prime}$ & $137^{\circ} 11^{\prime} 05^{\prime \prime}$ & 30 & 79 \\
\hline Togokusan & Tog & $35^{\circ} 15^{\prime} 08^{\prime \prime}$ & $137^{\circ} 03^{\prime} 13^{\prime \prime}$ & 34 & 40 \\
\hline Yatogawa & Yat & $35^{\circ} 11^{\prime} 25^{\prime \prime}$ & $137^{\circ} 06^{\prime} 55^{\prime \prime}$ & 77 & 77 \\
\hline \multicolumn{6}{|l|}{ Region B } \\
\hline Kurogawa & Kur & $34^{\circ} 38^{\prime} 44^{\prime \prime}$ & $137^{\circ} 14^{\prime} 30^{\prime \prime}$ & 29 & 29 \\
\hline Toshichibara & Tos & $34^{\circ} 40^{\prime} 39^{\prime \prime}$ & $137^{\circ} 14^{\prime} 46^{\prime \prime}$ & 30 & 130 \\
\hline Ikawazu & Ika & $34^{\circ} 37^{\prime} 11^{\prime \prime}$ & $137^{\circ} 08^{\prime} 56^{\prime \prime}$ & 27 & 30 \\
\hline Nagusa & Nag & $34^{\circ} 37^{\prime} 12^{\prime \prime}$ & $137^{\circ} 08^{\prime} 38^{\prime \prime}$ & 29 & 53 \\
\hline \multicolumn{6}{|l|}{ Region C } \\
\hline Asahidani & Asa & $34^{\circ} 58^{\prime} 37^{\prime \prime}$ & $136^{\circ} 31^{\prime} 39^{\prime \prime}$ & 29 & 29 \\
\hline Tabika & Tab & $35^{\circ} 04^{\prime} 41^{\prime \prime}$ & $136^{\circ} 30^{\prime} 43^{\prime \prime}$ & 31 & 51 \\
\hline
\end{tabular}

Population sizes are the numbers of reproductive individuals in the populations. 
and one (M6D8) developed for M. obovata (Isagi et al., 1999). PCR fragments were separated using a 3100 Genetic Analyzer and GeneScan software (Applied Biosystems) (see Setsuko et al., 2005, for details).

\section{Data analysis}

The following parameters were calculated at each locus and over all loci in each population using FSTAT ver. 2.9.3.2 (Goudet, 2001): allelic richness (AR), calculated with a fixed sample size of 27 (54 gene copies) (El Mousadik and Petit, 1996), gene diversity ( $\left.H_{\mathrm{E}} ; \mathrm{Nei}, 1987\right)$ and inbreeding coefficient $\left(F_{\mathrm{IS}}=1-H_{\mathrm{O}} / H_{\mathrm{E}}\right)$. Departures from Hardy-Weinberg equilibrium (HWE) at each locus and linkage disequilibrium between loci were tested in each population by an exact test using the Markov chain method implemented in GENEPOP ver. 3.4 (Raymond and Rousset, 1995), with sequential Bonferroni corrections (Rice, 1989). Assuming that the microsatellite loci used in this study were randomly sampled from an infinite number of loci, bootstrap resamplings among loci (20000 samples) were used to create 95\% bootstrap confidence intervals for $\mathrm{AR}, H_{\mathrm{E}}$ and $F_{\mathrm{IS}}$ for each population. Deviations of $F_{\mathrm{IS}}$ from zero over all loci in each population were tested using bootstrap confidence intervals of various percentages generated by the same bootstrap resampling method, with sequential Bonferroni corrections (Rice, 1989).

The total number of alleles detected $(A)$, allelic richness (AR), observed heterozygosity $\left(H_{\mathrm{O}}\right)$, average gene diversity within populations $\left(H_{\mathrm{S}}\right)$, gene diversity in the total populations $\left(H_{\mathrm{T}}\right)$, inbreeding coefficient $\left(F_{\mathrm{IS}}\right)$ and the coefficient of genetic differentiation among populations defined under the infinite allele model $\left(F_{\mathrm{ST}}\right.$; Weir and Cockerham, 1984) and the stepwise mutation model ( $R_{\mathrm{ST}}$; Slatkin, 1995; Rousset, 1996) were calculated across all populations at each locus and over all loci using FSTAT. Overall tests for departures from HWE across all over populations at each locus and over all loci were performed by Fisher's procedure (Fisher, 1970). The significance of population differentiation at each locus was tested by the log-likelihood $(G)$-based exact test (Goudet et al., 1996), with sequential Bonferroni corrections (Rice, 1989), using the Markov chain method implemented in GENEPOP, and its significance over all loci was tested by Fisher's procedure (Fisher, 1970). To test the presence of isolation-by-distance patterns in population differentiation, the Mantel test between population-pairwise geographic distances and genetic distances $\left(D_{\mathrm{A}}\right.$ distances; Nei et al., 1983) was applied. A dendrogram was constructed to interpret the relationships among populations by the neighbor-joining method (Saitou and Nei, 1987) based on $D_{\mathrm{A}}$ distances between populations using DISPAN (Ota, 1993). The node significances of the dendrogram were evaluated using bootstrap probabilities based on 10000 replicates.

Linear mixed-effect models were used to investigate the relationships between the level of genetic variation within each population and both its population size and degree of population isolation. We defined the size of each population as the number of reproductive individuals (s) within it, and its degree of population isolation as the number of populations within radii of $0.5-10.0 \mathrm{~km}$ with $0.5 \mathrm{~km}$ intervals (20 distance classes; $n 0.5-n 10.0$ ). We set the distance interval to $0.5 \mathrm{~km}$ since this was the minimum distance that significantly exceeded the measurement errors regarding the positions of populations. The number of surrounding populations was obtained from detailed distributional information of M. stellata populations published by the Japan Association for Shidekobushi Conservation (1996) together with our field observations. The population size and degree of population isolation were treated as fixed effects and the differences between loci as random effects. Two different response variables were used in the models: allelic richness (AR) and gene diversity $\left(H_{\mathrm{E}}\right)$. Data for $H_{\mathrm{E}}$ were arcsine-transformed to obtain closer approximations to normality. Forty-two candidate models with 1-3 fixed explanatory variables were constructed for each response variable. All models had fixed and random intercepts (the latter arose from the differences between loci). We estimated parameters in each model by the maximum likelihood method using R 2.3.1 (R Development Core Team, 2006).

To evaluate the candidate models, we calculated Akaike's information criterion (AIC; Akaike, 1973) values for each of them using the equation, $-2 \times(\log$ likelihood) $+2 \times$ (the number of estimated parameters). Models with low AIC values have higher likelihoods and contain smaller number of variables than models with higher values. A substantial advantage of using AIC, for the purposes of this study, is that it is valid for comparing non-nested models (Burnham and Anderson, 2002; Jhonson and Omland, 2004). The differences between the AIC values obtained for each of the models and the minimum AIC value $(\triangle \mathrm{AIC})$ were calculated, and each model with a $\triangle$ AIC value $\leqslant 2$ was considered to be one of the most parsimonious, and thus selected as one of the best models (Burnham and Anderson, 2002). We also calculated Akaike weights, from exp $[-0.5 \times(\triangle \mathrm{AIC}$ of the focal model $)] /$ $\Sigma \exp [-0.5 \times(\Delta \mathrm{AIC})]$, to assess the relative support for each model (Burnham and Anderson, 2002). Akaike weights range from zero to one and are normalized so that they sum to one over all candidate models. Akaike weights are convenient for comparing the relative likelihoods of models in a set of candidate models.

\section{Results}

\section{Within-population genetic variation}

Two hundred tests for deviations from HWE at each locus in each population were applied. Significant deviations were detected by 16 of these tests. There were no significant deviations at any locus across more than 3 populations, and 6 of the 16 significant deviations detected were at 6 loci in the Asahidani population. In addition, 900 tests for linkage disequilibrium between pairs of loci in each population were applied, 20 of which detected significant deviation from equilibrium, but the deviation was not significant for any pairs of loci across more than 3 populations. The loci used in this study exhibited high polymorphism (Table 2). The total number of alleles detected $(A)$ and average gene diversity within populations $\left(H_{\mathrm{S}}\right)$ at each locus across all populations were, on average, 22.1 and 0.719, respectively. $F_{\mathrm{IS}}$ values across all populations were positive at nine loci and over all loci, and departures from HWE were significant at the same nine loci and 
Table 2 Within- and among-population genetic variation in the 20 investigated Magnolia stellata populations

\begin{tabular}{|c|c|c|c|c|c|c|c|c|c|c|}
\hline Locus & A & $A R$ & $\mathrm{H}_{O}$ & $\mathrm{H}_{S}$ & $\mathrm{H}_{T}$ & $\mathrm{~F}_{I S}$ & Tests for $H W E^{\mathrm{a}}$ & $\mathrm{F}_{S T}$ & $\mathrm{R}_{S T}$ & Tests for differentiation ${ }^{\mathrm{b}}$ \\
\hline stm0148 & 26 & 8.61 & 0.690 & 0.747 & 0.883 & 0.076 & $* * *$ & 0.166 & 0.207 & $* * *$ \\
\hline stm0184 & 18 & 6.21 & 0.629 & 0.648 & 0.827 & 0.029 & * & 0.224 & 0.251 & $* * *$ \\
\hline stm0191 & 19 & 8.46 & 0.725 & 0.780 & 0.894 & 0.071 & $* *$ & 0.130 & 0.241 & $* * *$ \\
\hline stm0222 & 25 & 7.57 & 0.653 & 0.739 & 0.882 & 0.116 & $* * *$ & 0.159 & 0.184 & $* * *$ \\
\hline stm0223 & 14 & 5.16 & 0.557 & 0.554 & 0.810 & -0.005 & & 0.291 & 0.316 & $* * *$ \\
\hline stm0251 & 17 & 7.06 & 0.663 & 0.733 & 0.874 & 0.095 & $* * *$ & 0.167 & 0.365 & $* * *$ \\
\hline stm0334 & 27 & 9.27 & 0.711 & 0.789 & 0.927 & 0.099 & $* *$ & 0.151 & 0.209 & $* * *$ \\
\hline stm0353 & 21 & 7.69 & 0.696 & 0.751 & 0.897 & 0.073 & * & 0.163 & 0.300 & $* * *$ \\
\hline stm0423 & 31 & 8.13 & 0.689 & 0.749 & 0.937 & 0.080 & $* *$ & 0.201 & 0.292 & $* * *$ \\
\hline M6D8 & 23 & 6.35 & 0.649 & 0.698 & 0.887 & 0.070 & $* *$ & 0.211 & 0.377 & $* * *$ \\
\hline Mean & 22.1 & 7.45 & 0.666 & 0.719 & 0.882 & 0.074 & $* * *$ & 0.185 & 0.274 & $* * *$ \\
\hline
\end{tabular}

Abbreviations: $A$, the total number of alleles detected; $\mathrm{AR}$, allelic richness; $H_{\mathrm{O}}$, observed heterozygosity; $H_{\mathrm{S}}$, average gene diversity within populations; HWE, Hardy-Weinberg equilibrium; $H_{\mathrm{T}}$, gene diversity in the total populations; $F_{\mathrm{IS}}$, inbreeding coefficient; $F_{\mathrm{ST}}$ and $R_{\mathrm{ST}}$, the coefficients of genetic differentiation among populations defined under the infinite allele model and the stepwise mutation model, respectively.

Sequential Bonferroni correction (Rice, 1989) was used to determine significance in the multiple tests.

${ }^{*} P<0.05 ;{ }^{* *} P<0.01 ; * * * P<0.001$.

${ }^{a}$ Departures from HWE at each locus and over all loci were tested by Fisher's procedure (Fisher, 1970), which combined probabilities from exact tests for departures from HWE in each population.

${ }^{\mathrm{b}}$ The significance of population differentiation at each locus was tested by the log-likelihood (G)-based exact test (Goudet $e$ al., 1996), and that over all loci was tested by Fisher's procedure (Fisher, 1970).

over all loci. The allelic richness (AR) and gene diversity $\left(H_{\mathrm{E}}\right)$ of the populations ranged from 2.99 to 11.64 and from 0.517 to 0.863 , with mean values of 7.45 and 0.719 , respectively (Figures 2a and b). Levels of withinpopulation genetic variation were generally higher in populations in region A (although they were substantially lower in three populations in this region: Iji, Obora and Kotohira) than in populations in regions $B$ and $C$, except for the Tabika population. Unexpectedly, the Tabika population showed the highest genetic variation $\left(H_{\mathrm{E}}=0.863\right.$ and $\left.\mathrm{AR}=11.64\right)$ of all the populations, even though it was highly isolated from other populations (Figure 1) and its population size was modest (Table 1).

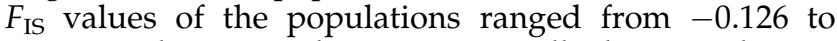
0.297, and averaged 0.073 over all the populations (Figure 2c). Significant positive deviations of $F_{\text {IS }}$ values from zero were detected in three populations (Chikusuiike, Kotohira and Asahidani).

\section{Among-population genetic variation}

All the loci used in this study showed significant population differentiation $(P<0.001)$ and the values of $F_{\mathrm{ST}}$ and $R_{\mathrm{ST}}$ over all loci were 0.185 and 0.274 , respectively (Table 2). There was also a significant correlation between pairwise-population geographic distances and $D_{\mathrm{A}}$ distances $\left(R^{2}=0.579, P<0.001\right.$, Mantel test; Figure 3$)$. The neighbor-joining tree based on $D_{\mathrm{A}}$ distances between populations seems to reflect the populations' geographical distribution (Figures 1 and 4). Four nodes of this tree were supported with high bootstrap probabilities (more than $88 \%$ ). These nodes correspond to geographical locations at the edge of the eastern Gifu Prefecture (98\%), the root of the Atsumi Peninsula (90\%) and two within the peninsula (88 and $100 \%$ ).

Factors influencing the level of within-population genetic variation

All regression coefficients of fixed explanatory variables (c, s, n0.5-n10.0) against the two response variables
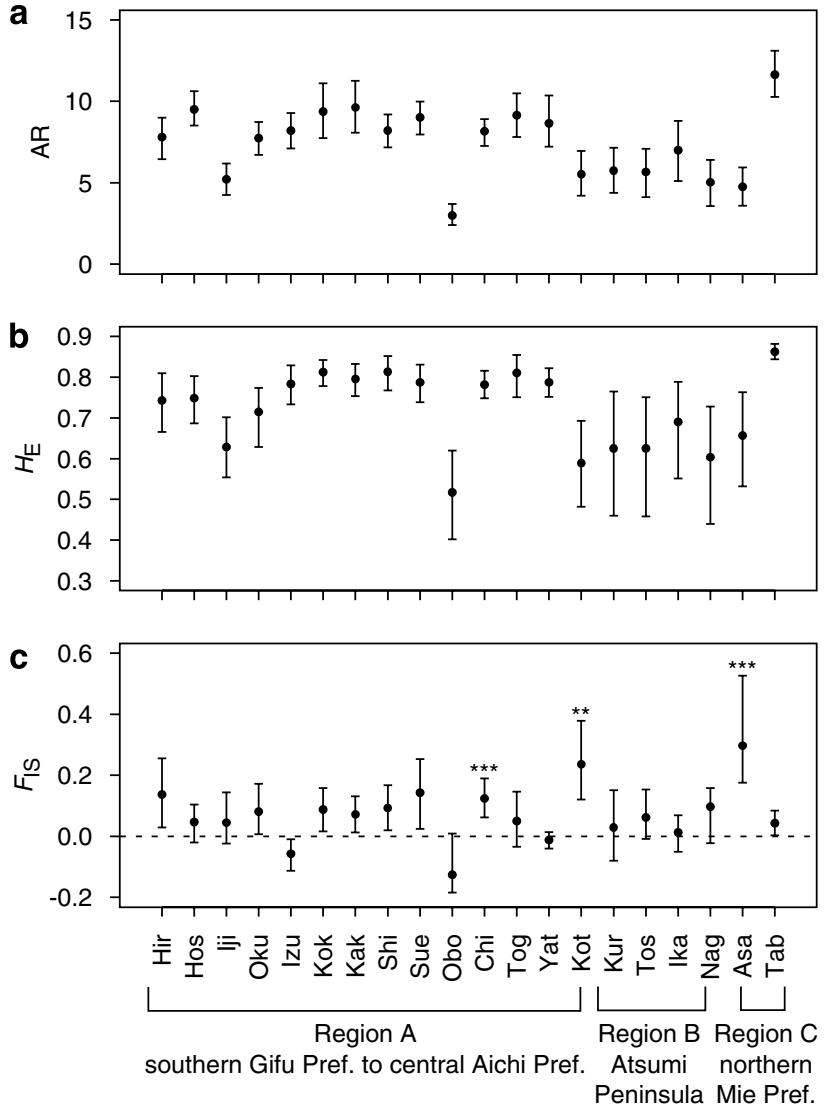

Figure 2 Allelic richness (a), gene diversity (b) and inbreeding coefficient (c) in the 20 investigated Magnolia stellata populations. Dots and bars show values calculated using the original data set and their $95 \%$ bootstrap confidence intervals were estimated by 20000 bootstrap resamplings among loci, respectively. Deviations of $F_{\text {IS }}$ from zero at each population were tested using bootstrap confidence intervals of various percentages generated by the same bootstrap resampling method, with sequential Bonferroni corrections (Rice, 1989). ${ }^{* *} P<0.01 ;{ }^{* *} P<0.001$. Populations are represented by the codes listed in Table 1 . 
(AR and $H_{\mathrm{E}}$ ) estimated by the maximum likelihood method were positive. The models, providing the best explanations for $\mathrm{AR}$ and $H_{\mathrm{E}}$, had the same parameters (s and $n 0.5$ ) with $\Delta \mathrm{AIC} \leqslant 2$ (Table 3 ). Akaike weights of these models were 0.611 and 0.237 for AR and $H_{\mathrm{E}}$, respectively. The models had two fixed explanatory

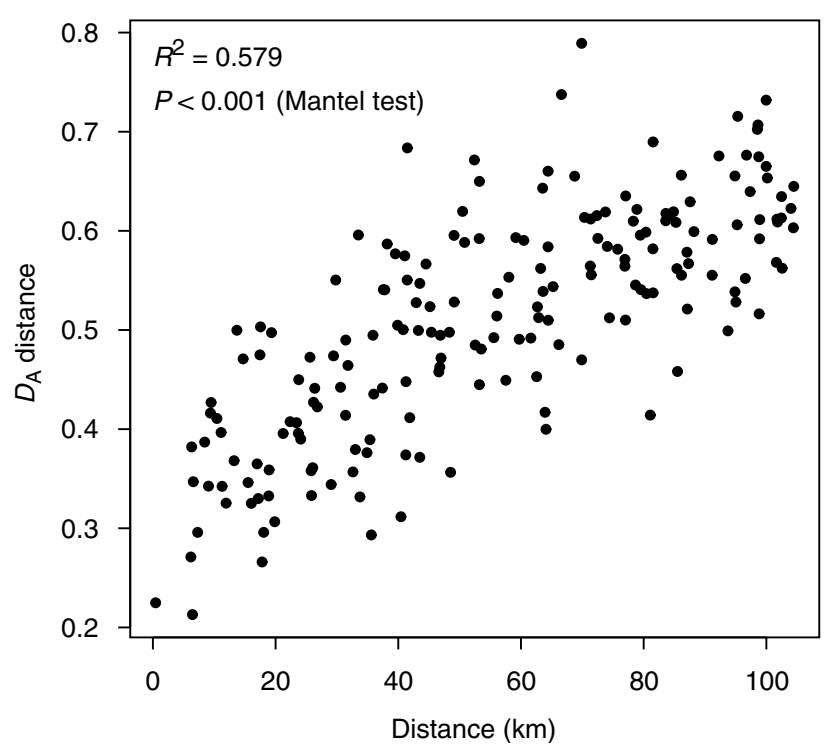

Figure $3 D_{\mathrm{A}}$ distances between the 20 investigated populations of Magnolia stellata versus geographical distances between them.

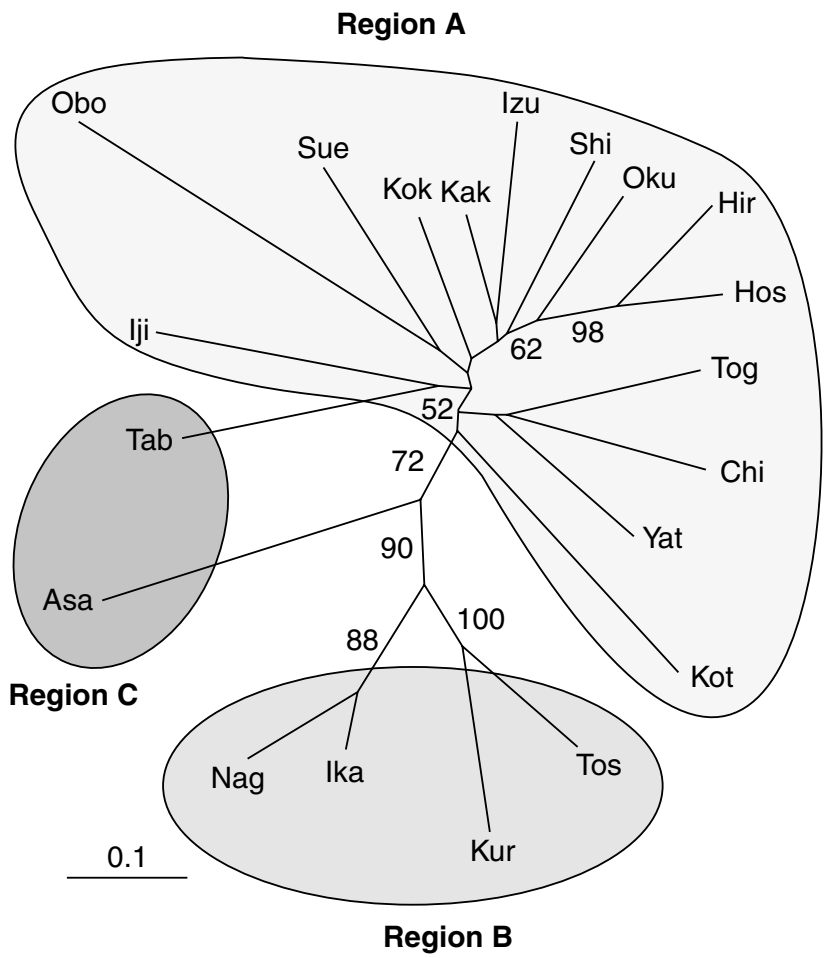

Figure 4 Neighbor-joining tree constructed using $D_{\mathrm{A}}$ distances between the 20 investigated Magnolia stellata populations. The numbers shown are bootstrap probabilities exceeding $50 \%$ based on 10000 replicates. The length of the bar is equal to the genetic distance of 0.1 . Populations are represented by the codes listed in Table 1 . variables: the population size (regression coefficients $\pm 95 \%$ confidence intervals: $0.0106 \pm 0.0047$ for AR; $0.0004 \pm 0.0003$ for $H_{\mathrm{E}}$ ) and the number of surrounding populations within a radius of $0.5 \mathrm{~km}$ around the focal population $(0.3657 \pm 0.2080$ for $\mathrm{AR}$; $0.0230 \pm 0.0143$ for $H_{\mathrm{E}}$ ) (Table 4).

\section{Discussion}

Within- and among-population genetic variation

The level of within-population genetic variation tended to be higher for populations in region $\mathrm{A}$ than for populations in regions $\mathrm{B}$ and $\mathrm{C}$, in accordance with the results of previous studies (Kawahara and Yoshimaru, 1995; Ueno et al., 2005). This trend may be partly due to region $\mathrm{A}$ being central to the species' range, while regions $B$ and $C$ are marginal, and partly due to the populations in regions $B$ and $C$ being more isolated from one another than those in region A. A finding that was not observed in the previous studies was that some populations in region A (Iji, Obora and Kotohira)

Table 3 The best models (in bold), and four next best models, explaining the levels of within-population genetic variation of the 20 investigated Magnolia stellata populations, selected according to Akaike's information criterion (AIC)

\begin{tabular}{|c|c|c|c|c|c|c|}
\hline \multirow[t]{2}{*}{ Model rank } & \multicolumn{3}{|c|}{$A R$} & \multicolumn{3}{|c|}{ Arcsine $\left(\mathrm{H}_{E}\right)$} \\
\hline & Model & $\triangle A I C$ & $\begin{array}{l}\text { Akaike } \\
\text { weight }\end{array}$ & Model & $\triangle A I C$ & $\begin{array}{l}\text { Akaike } \\
\text { weight }\end{array}$ \\
\hline 1 & $c+s+n 0.5$ & 0.000 & 0.611 & $c+s+n 0.5$ & 0.000 & 0.237 \\
\hline 2 & $c+s+n 1.5$ & 4.824 & 0.055 & $c+s+n 1.5$ & 2.980 & 0.05 \\
\hline 3 & $c+s+n 1.0$ & 5.329 & 0.043 & $c+s+n 2.0$ & 3.071 & 0.05 \\
\hline 4 & $c+s+n 2.0$ & 5.500 & 0.039 & $c+s+n 3.0$ & 3.186 & 0.04 \\
\hline 5 & $c+s+n 2.5$ & 6.559 & 0.023 & $c+s+n 3.5$ & 3.382 & 0.044 \\
\hline
\end{tabular}

Abbreviations: AR, allelic richness; $H_{\mathrm{E}}$, gene diversity; $\triangle \mathrm{AIC}$, the difference in AIC between the model considered and the most parsimonious one; Akaike weight, the relative likelihood of the model; $c$, intercept; s, population size; $n 0.5, n 1.0, n 1.5, n 2.0, n 2.5, n 3.0$ and $n 3.5$, the number of surrounding populations within a radius of $0.5,1.0,1.5,2.0,2.5,3.0$ and $3.5 \mathrm{~km}$ around the focal population, respectively.

All regression coefficients of fixed explanatory variables were positive.

Table 4 Fixed-effect explanatory variables of the linear mixed-effect models (random effect: locus) that best explained the level of within-population genetic variation of the 20 investigated Magnolia stellata populations, selected according to Akaike's information criterion (AIC)

\begin{tabular}{lcccccc}
\hline $\begin{array}{l}\text { Response } \\
\text { variables }\end{array}$ & $\begin{array}{c}\text { Explanatory } \\
\text { variables }\end{array}$ & $\begin{array}{c}\text { Regression } \\
\text { coefficients }\end{array}$ & s.e. & $d f$ & $t$ & $\mathrm{P}$ \\
$\mathrm{AR}$ & $\mathrm{c}$ & 5.8251 & 0.4865 & 188 & 11.974 & 0.000 \\
& $\mathrm{~S}$ & 0.0106 & 0.0024 & 188 & 4.398 & 0.000 \\
& $n 0.5$ & 0.3657 & 0.1061 & 188 & 3.448 & 0.001 \\
Arcsine $\left(H_{\mathrm{E}}\right)$ & $\mathrm{c}$ & 0.9385 & 0.0332 & 188 & 28.275 & 0.000 \\
& $\mathrm{~S}$ & 0.0004 & 0.0002 & 188 & 2.601 & 0.010 \\
& $n 0.5$ & 0.0230 & 0.0073 & 188 & 3.159 & 0.002
\end{tabular}

Abbreviations: AR, allelic richness; $c$, intercept; $\mathrm{df}$, degrees of freedom; $H_{\mathrm{E}}$, gene diversity; $n 0.5$, the number of surrounding populations within a radius of $0.5 \mathrm{~km}$ around the focal population; $s$, population size. 
showed substantially lower variation than the others in this region, even lower in some respects than those in regions $B$ and $C$ (Figure 2). One of these populations is located at an unusually high altitude (the Iji population, located $700 \mathrm{~m}$ above sea level, while most populations are located $200-500 \mathrm{~m}$ above sea level) and the other two (Obora and Kotohira) at the edges of the species' range. Thus, these populations are in isolated environments, like those in regions $B$ and $C$, and this may account in large part for their low levels of variation. We discuss the influence of isolation on the level of within-population genetic variation in the following section.

Interestingly, although the Tabika population was highly isolated and did not have a large population size, it showed the highest within-population genetic variation. High genetic variation in this population has also been revealed by nuclear microsatellite analyses in a previous study (in which it was called the Komono population; Ueno et al., 2005). Ueno et al. (2005) also examined cpDNA variation in 11 populations, and found that the level of variation was unusually high in the Tabika population. The unusually high genetic variation in the population could not be explained by contemporary gene flow due to its isolated distribution and its modest current size. Therefore, the reasons for it may be related to historical dynamics of the population and surrounding populations in region $C$.

Significant positive values of $F_{\mathrm{IS}}$ estimated across all populations at nine loci (as indicated by their significant departures from HWE), and those over all loci in three populations, indicate an excess of homozygotes compared to expectations under HWE, main causes of which include inbreeding, population substructure and the presence of null alleles. $M$. stellata produces protogynous, hermaphrodite flowers that prevent autogamous selfing, but its asynchronous flowering within individuals leads to geitonogamous selfing (Hirayama et al., 2005). Selfing rates of $26.1-38.8 \%$ at the mature seed stage (Hirayama et al., 2007) and 5.7\% at the germinated seedling stage (Setsuko et al., 2007) have been reported. In addition, the Asahidani population showed significant deviations from HWE at six of the loci used in this study and the highest value of $F_{\mathrm{IS}}$ among the studied populations. These features were probably not due to locus characteristics such as the presence of null alleles, but to population characteristics such as inbreeding and population substructure. However, genotype frequencies at the locus stm0353 significantly deviated from HWE in three adjacent populations (Sue, Shizuno and Chikusui-ike), suggesting the presence of null alleles at the locus that are regionally distributed over the three populations.

Population differentiation among the 20 populations was significant $\left(F_{\mathrm{ST}}=0.185\right.$ and $\left.R_{\mathrm{ST}}=0.274\right)$, and a significant isolation-by-distance pattern was also detected. The value of $F_{\mathrm{ST}}$ obtained in this study is very similar to that obtained by Ueno et al. (2005) using nuclear microsatellites $\left(\Phi_{\mathrm{SC}}\right.$, an analog to $\left.F_{\mathrm{ST}}=0.18\right)$, but lower than that found by Kawahara and Yoshimaru (1995) using allozymes $\left(G_{\mathrm{ST}}\right.$, an analog to $\left.F_{\mathrm{ST}}=0.254\right)$. Values of $F_{\mathrm{ST}}$ and $G_{\mathrm{ST}}$ cannot be simply compared between loci if the loci to be compared exhibit different levels of within-population genetic variation (Hedrick, 2005), as in the material examined here, since there were considerably higher values of $H_{\mathrm{S}}$ at microsatellite loci
(0.719, this study; 0.58, Ueno et al., 2005) than at allozyme loci (0.092, Kawahara and Yoshimaru, 1995). Hedrick (2005) addressed this problem, and proposed a standardized measure $\left(G_{\mathrm{ST}}^{\prime}\right)$, which allows more appropriate comparisons between loci that have different levels of genetic variation. Using the microsatellite data in this study and the previous allozyme data (Kawahara and Yoshimaru, 1995), $G_{\text {ST }}^{\prime}$ values were estimated to be 0.683 and 0.283 , respectively. Genetic differentiation for microsatellite loci was found to be more than twice that for allozyme loci.

The separation of populations in region B (the Atsumi Peninsula) from those in the other regions was supported by a bootstrap probability of $90 \%$, indicating that the differentiation of populations in region B from the populations in the other regions is due to their geographical isolation. Furthermore, there was significant support, with a bootstrap probability of $100 \%$, for the separation of populations (Kurogawa and Toshichibara) at the root of the Astumi Peninsula from even the populations (Ikawazu and Nagusa) at the tip of the same peninsula, indicating that there was little gene flow between populations at the tip and root of the peninsula, although they were located close to each other (about $5 \mathrm{~km}$ apart).

\section{Factors influencing the level of within-population genetic variation}

This study demonstrated significant relationships of genetic variation with population size and the degree of population isolation in $M$. stellata populations using linear mixed models. The model with population size and degree of population isolation (the number of surrounding populations in a radius of $0.5 \mathrm{~km}$ around the focal population) as fixed explanatory variables was selected as the best for explaining the level of withinpopulation genetic variation in both response variables, $\mathrm{AR}$ and $H_{\mathrm{E}}$. The regression coefficients of the best models are all positive, implying that populations with large sizes and high numbers of surrounding populations within a radius of $0.5 \mathrm{~km}$ should have high levels of genetic variation. The best models predict that a decrease in population size, $s$ (which ranged from 29 to 339 individuals among the studied populations), of 100 individuals corresponds to reductions in $\mathrm{AR}$ and $H_{\mathrm{E}}$ of 1.060 and 0.039, respectively, and a decrease in the number of populations within a radius of $0.5 \mathrm{~km}, n 0.5$ (which ranges from 0 to 7 among the populations), of five populations corresponds to reductions in $\mathrm{AR}$ and $H_{\mathrm{E}}$ of 1.829 and 0.113 , respectively.

Many studies have reported significant relationships between population size and genetic variation (for example, Young et al., 1999; Galeuchet et al., 2005; Gao, 2005; Leim et al., 2006). However, a previous study on M. stellata published by Nakashima and Sakai (2003) did not detect such a relationship, possibly because the measure of population size they used was not the number of reproductive individuals but the number of individuals within populations. In contrast to the multitude of reported relationships between population size and genetic variation, few studies have detected significant relationships between the degree of population isolation and genetic variation (Cruzan, 2001; $\mathrm{Lu}$ et al., 2005). Since it is more difficult to measure the 
degree of population isolation than population size, good measures for quantifying the degree of population isolation have not yet been established. However, we detected significant relationships between the degree of population isolation and genetic variation, using the number of surrounding populations as the measure of isolation, whereas the distance from the nearest population was used in many previous studies (for example, Llorens et al., 2004; Galeuchet et al., 2005; Lu et al., 2005). Thus, the detection of a significant relationship in this study, and the failure of many of the cited studies to detect such relationship, supports the assertion by Moilanen and Nieminen (2002) that the number of surrounding populations is a much better indicator of isolation than the distance from the nearest population. In addition, Cruzan (2001) reported significant relationships between the degree of population isolation and genetic variation, using the number of surrounding populations. Important components affecting the degree of population isolation are likely to be the number and distribution of population in proximity to the focal population. However, the most important of these components appears to be the number of populations in the proximity of the focal population, especially for species that form hierarchical metapopulation structure, such as M. stellata.

The area encompassed by a radius of $0.5 \mathrm{~km}$ around each population, selected in the best model in this study, may cover the range of metapopulations in $M$. stellata because the number of populations within the area had significant effects on within-population genetic variation. This is consistent with observations published by Setsuko et al. (2007), who found the maximum distance that pollen was directly transferred across local populations within a metapopulation of the species to be ca. $420 \mathrm{~m}$, although long-distance gene flow may occur over $500 \mathrm{~m}$, at least through seed dispersal by birds. However, gene flow between populations within radii of $0.5 \mathrm{~km}$ in metapopulations may principally influence the level of genetic variation within populations in the species.

\section{Conservation implications}

The populations distributed in region $\mathrm{A}$ have been shown to contain higher genetic variation than the populations distributed in regions $B$ and $C$, but even in region $A$ populations located at an unusually high altitude (Iji) or at the western and southern edges of the range (Obora and Kotohira) showed similar levels of genetic variation to those in the populations distributed in regions $B$ and $C$. These populations with low genetic variation (especially the Obora population) have small population sizes and high degrees of population isolation, and may be highly prone to further reductions in genetic variation through random genetic drift (Frankham et al., 2002; Primack, 2002; Hartl and Clark, 2006). Therefore, further reductions in the numbers of individuals in these populations should be avoided to prevent their extinction.

The neighbor-joining tree indicates significant differentiation between populations at the edge of the eastern Gifu Prefecture and the other regions, the Atsumi Peninsula and the other regions, and between the tip and root in the peninsula. If trees are to be transplanted from other populations to these populations to counter population decline in the future, use of trees from populations outside the regions should be avoided. In addition, even within the Atsumi peninsula, use of trees from neighboring populations would be most appropriate for transplanting.

In attempts to conserve rare species, only specific, large populations are often designated as conservation targets, although the surrounding populations may be important as sources of pollens and seeds with different genetic variations (Setsuko et al., 2007). We have found that not only the number of reproductive individuals within the focal population but also the number of surrounding populations within a radius of $0.5 \mathrm{~km}$ around it influences its level of within-population genetic variation. These findings support the notion that the metapopulation structure of $M$. stellata should be retained in attempts to conserve the species, and suggest that an appropriate conservation strategy could include the designation of areas encompassed by circles with a radius of $0.5 \mathrm{~km}$ as conservation units. Certain $M$. stellata populations have been designated as natural monuments for conservation purposes, which we support, but such measures only protect specific local populations that may not be sustainable in isolation. Thus, to ensure the long-term conservation of populations of $M$. stellata, the importance of surrounding populations around them must be considered.

\section{Acknowledgements}

We are grateful to the members of the Laboratory of Forest Ecology and Physiology of Nagoya University for useful discussions. We also thank several Education Offices of local governments for permitting us to collect the materials, $\mathrm{K}$ Ishida and $\mathrm{K}$ Hirayama for their help in the collection and two anonymous reviewers for their valuable comments on a previous draft of the manuscript. Financial support was provided by a Grant-in-Aid for Scientific Research (no. 16380100) from the Japan Society for the Promotion of Science.

\section{References}

Akaike H (1973). Information theory and an extension of the maximum likelihood principle. In: Petrov BN, Csaki F (eds). Second International Symposium on Information Theory. Akademinai Kiado: Budapest, Hungary. pp 267-281.

Burnham KP, Anderson DR (2002). Model Selection and Multimodel Inference: a Practical Information-Theoretic Approach, 2nd edn. Springer: New York, USA.

Callaway DJ (1994). The World of Magnolias. Timber Press: Oregon, USA, 260pp.

Cruzan MB (2001). Population size and fragmentation thresholds for the maintenance of genetic diversity in the herbaceous endemic Scutellaria montana (Lamiaceae). Evolution 55: 1569-1580.

El Mousadik A, Petit RJ (1996). High level of genetic differentiation for allelic richness among populations of the argan tree [Argania spinosa (L.) Skeels] endemic to Morocco. Theor Appl Genet 92: 832-839.

Ellstrand NC, Elam DR (1993). Population genetic consequences of small population size: implications for plant conservation. Annu Rev Ecol Syst 24: 217-242.

Environment Agency of Japan (2000). Threatened Wildlife of Japan-Red Data Book, Vol. 8 Vascular Plants. Japan Wildlife Research Center: Tokyo, Japan (in Japanese). 
Fisher RA (1970). Statistical Methods for Research Workers, 14th edn. Oliver and Boyd: Edinburgh, UK.

Frankham R (2005). Genetics and extinction. Biol Conserv 126: 131-140.

Frankham R, Ballou JD, Briscoe DA (2002). Introduction to Conservation Genetics. Cambridge University Press: Cambridge, UK, 617pp.

Galeuchet DJ, Perret C, Fischer M (2005). Microsatellite variation and structure of 28 populations of the common wetland plant, Lychnis floscuculi L. in a fragmented landscape. Mol Ecol 14: 991-1000.

Gao LZ (2005). Microsatellite variation within and among populations of Oryza officinalis (Poaceae), an endangered wild rice from China. Mol Ecol 14: 4287-4297.

Gilpine ME, Soule ME (1986). Minimum viable populations: process of species extinction. In: Soule ME (ed). Conservation Biology: the Science of Scarcity and Diversity. Sinauer Associations: Sunderland, Massachusetts, USA. pp 19-34.

Gotoh T, Hamashima S, Kikuchi T (1998). A vegetative regeneration habit of Magnolia tomentosa Thunb. J Phytogeogr Taxonomy 46: 205-209.

Goudet J (2001). FSTAT, a program to estimate and test genetic diversities and fixation indices (version 2.9.3). Available from http://www2.unil.ch/popgen/softwares/fstat.htm.

Goudet J, Raymond M, deMeeus T, Rousset F (1996). Testing differentiation in diploid populations. Genetics 144: 1933-1940.

Hartl DL, Clark A (2006). Principles of Population Genetics, 4th edn. Sinauer Associations: Sunderland Massachusetts, USA.

Hedrick PW (2005). A standardized genetic differentiation measure. Evolution 59: 1633-1638.

Hirayama K, Ishida K, Setsuko S, Tomaru N (2007). Reduced seed production, inbreeding, and pollen shortage in a small population of a threatened tree, Magnolia stellata. Biol Conserv 136: 315-323.

Hirayama K, Ishida K, Tomaru N (2005). Effects of pollen shortage and self-pollination on seed production of an endangered tree, Magnolia stellata. Ann Bot 95: 1009-1015.

Isagi Y, Kanazashi T, Suzuki W, Tanaka H, Abe T (1999). Polymorphic microsatellite DNA markers for Magnolia obovata Thunb. and their utility in related species. Mol Ecol 8: $685-702$.

Japan Association for Shidekobushi Conservation (1996). Wild Stand of Shidekobushi (Star Magnolia) in Japan. Japan Association for Shidekobushi Conservation: Mizunami, Gifu, Japan (in Japanese), 217pp.

Jhonson JB, Omland KS (2004). Model selection in ecology and evolution. Trends Ecol Evol 19: 101-108.

Kawahara T, Yoshimaru H (1995). Magnolia tomentosa and its genetic variation. Puranta 39: 9-13 (in Japanese).

Leim R, Mutikainen P, Koricheva J, Fischer M (2006). How general are positive relationships between plant population size, fitness and genetic variation? J Ecol 94: 942-952.

Llorens TM, Ayre DJ, Whelan RJ (2004). Evidence for ancient genetic subdivision among recently fragmented populations of the endangered shrub Grevillea caleyi (Proteaceae). Heredity 92: 519-526.

Lu Y, Waller DM, David P (2005). Genetic variability is correlated with population size and reproduction in American wild-rice (Zizania palustris ver. palustris, Poaceae) populations. Am J Bot 92: 990-997.
Moilanen A, Nieminen M (2002). Simple connectivity measures in spatial ecology. Ecology 83: 1131-1145.

Murray MG, Thompson WF (1980). Rapid isolation of high molecular weight plant DNA. Nucleic Acids Res 8: 4321-4325.

Nakashima M, Sakai Y (2003). Genetic diversity of Magnolia stellata (Magnoliaceae), distributed in Tono region. Report of Gifu Prefectural Research Institute for Forests 32: 15-20 (in Japanese).

Nei M (1987). Molecular Evolutionary Genetics. Columbia University Press: New York, USA.

Nei M, Tajima F, Tateno Y (1983). Accuracy of estimated phylogenetic trees from molecular data. J Mol Evol 19: 153-170.

Ota T (1993). DISPAN: a computer program for the genetic distance and phylogenetic analysis. Available from http:// www.bio.psu.edu/People/Faculty/Nei/Lab/software.htm.

Ouborg NJ, Vergeer P, Mix C (2006). The rough edges of the conservation genetics paradigm for plants. J Ecol 94: 1233-1248.

Primack RB (2002). Essentials of Conservation Biology, 3rd edn. Sinauer Associates: Sunderland, Massachusetts, USA.

R Development Core Team (2006). R: A Language and Environment for Statistical Computing. R Foundation for Statistical Computing: Vienna, Austria.

Raymond M, Rousset F (1995). GENEPOP (version 1.2): population genetics software for exact tests and ecumenicism. J Hered 86: 248-249.

Rice WR (1989). Analyzing tables of statistical tests. Evolution 43: $223-225$.

Rousset F (1996). Equilibrium values of measures of population subdivision for stepwise mutation processes. Genetics 142 1357-1362.

Saitou N, Nei M (1987). The neighbor-joining method: a new method for reconstructing phylogenetic trees. Mol Biol Evol 4: 406-425.

Setsuko S, Ishida K, Tomaru N (2004). Size distribution and genetic structure in relation to clonal growth within a population of Magnolia tomentosa Thunb. (Magnoliaceae). Mol Ecol 13: 2645-2653.

Setsuko S, Ishida K, Ueno S, Tsumura Y, Tomaru N (2007). Population differentiation and gene flow within a metapopulation of a threatened tree, Magnolia stellata (Magnoliaceae). Am I Bot 94: 128-136.

Setsuko S, Ueno S, Tsumura Y, Tomaru N (2005). Development of microsatellite markers in Magnolia stellata (Magnoliaceae), a threatened Japanese tree. Conserv Genet 6: 317-320.

Silvertown J, Charlesworth D (2001). Introduction to Plant Population Biology, 4th edn. Blackwell Science: Oxford, UK, 347pp.

Slatkin M (1995). A measure of population subdivision based on microsatellite allele frequencies. Genetics 139: 457-462.

Ueda K (1988). Star magnolia (Magnolia tomentosa) an indigenous Japanese plant. J Arnold Arboretum 69: 281-288.

Ueno S, Setsuko S, Kawahara T, Yoshimaru H (2005). Genetic diversity and differentiation of the endangered Japanese endemic tree Magnolia stellata using nuclear and chloroplast microsatellite markers. Conserv Genet 6: 563-574.

Weir BS, Cockerham CC (1984). Estimating F-statistics for the analysis of population structure. Evolution 38: 1358-1370.

Young AG, Brown AHD, Zich FA (1999). Genetic structure of fragmented populations of the endangered daisy Rutidosis leptorrhynchoides. Conserv Biol 13: 256-265. 